\title{
A 5 years missed Nelatone tube as a stent ureter which has been inserted post peylonephertomy
}

\begin{abstract}
Stenting of ureter is necessary sometimes after operation of ureter for prevention of leak and obstruction. It has been advised that maximum after three months the stet must be removed. Many complications have been described for stentor $\mathrm{jj}$ in ureter even death may be associated with double join this paper we present a case with nelatone tube which has been inserted five years ago.
\end{abstract}

Keywords: stent, DJ, ureter stent, missed stent, missed DJ
Volume 9 Issue 4 - 2019

\author{
Afshar Zomorrodi \\ Head of organ transplantation department, Tabriz Medical \\ science university, Iran
}

\begin{abstract}
Correspondence: Afshar Zomorrodi, Professor of urology and kidney transplant surgeon, Head of organ transplantation department, imam Reza hospital,Tabriz Medical Science University, Iran, Email dr_zomorrodi@yahoo.com
\end{abstract}

Received: August 09, 2019 | Published: August 16,2019

\section{Case report}

A 40 years' man with a history of nephrolithiasis referred for LUTS and bladder stone in evaluation of bladder stone it was discovered that there is a. stent in urinary system of left kidney (Figure 1). The patient was candidate for ESWL after once time ESWL he was carried out for cystoscopy to removing stent and remained of bladder stone. In cystoscopy with covering of antibiotic nelatone of ureter easily removed which was intact (Figure 2) and also the remained of bladder stone.

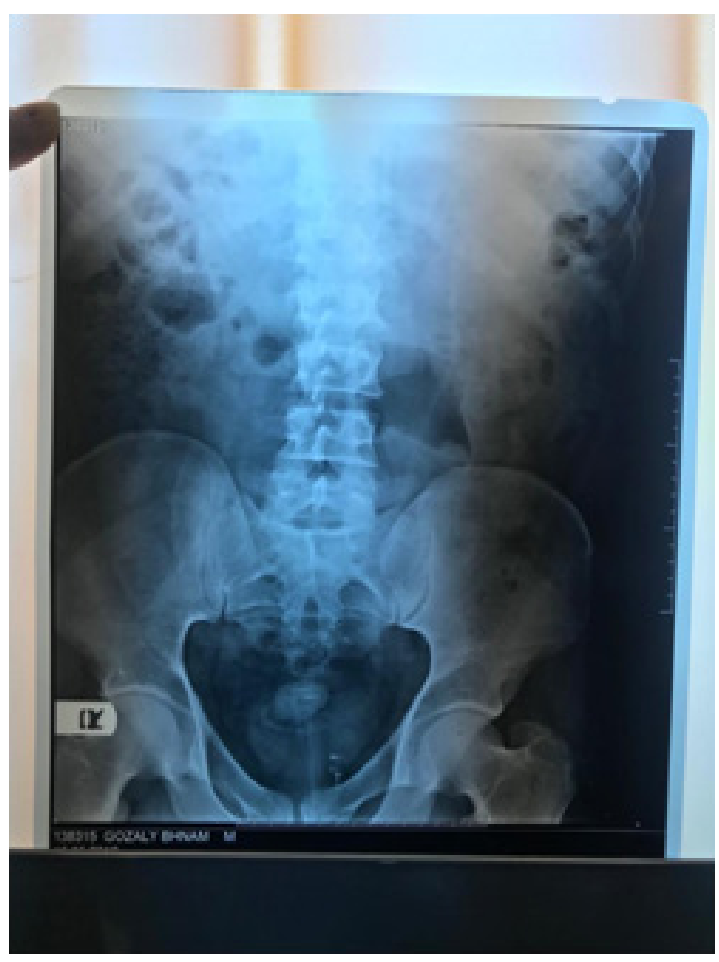

Figure I KUB: nelatone with left kidney.

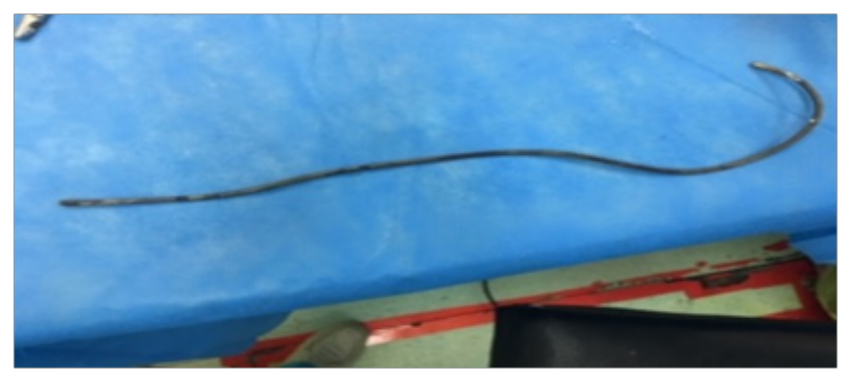

Figure 2 Nelatone tube after 5 years missed, intact stent with a little encrustation.

\section{Discussion}

Stenting of ureter is important for prevention of leak and obstruction of ureter. ${ }^{1,2}$ In almost all of ureter anastomosing of ureter in grafting of kidney stent is placed. Although stent prevents obstruction and helps to repairmen of ureter it may induce obstruction, infection and stone making. Time duration of stent and kind of stent, size of stent are important for inducing complication. If longer time stent remained in ureter may be associated with fragmentation and infection and stone. Late complication including stone, infection and migration and fragmentation in one third of patient maybe occurred. ${ }^{3}$ Any complicated obstruction of urinary system maybe need for inserting stent for treatment. ${ }^{4-6}$ Encrustation is precipitation of calcium and oxalate on biofilm on surface of stent, for forming biofilm on surface of stent it is necessary to adherence protein that it is presence in the urine and production of bacteria. ${ }^{7}$ Encrustation of stent depends to many factor including: time of presence of stent in system, history of nephrolithiasis, infection, biofilm, pregnancy and kind of stent. Forgotten stent may have many complications even death. ${ }^{8}$ In this case the stent was Nealtone tube which after 5 years forgotten it was not associate with a very big problem.

\section{Acknowledgments}

None. 


\section{Funding}

None.

\section{Conflict of interest}

There is no conflict of interest.

\section{References}

1. Siggers JH, Waters $\mathrm{S}$, Wattis $\mathrm{J}$, et al. Flow dynamics in a stented ureter Math Med Biol. 2009;26(1):1-24.

2. Ramsay JW, Payne SR, Gosling PT, et al. The effects of double J stenting on unobstructed ureters. An experimental and clinical study. Br J Urol. 1985;57(6):630-634

3. Ringel A1, Richter S, Shalev M, et al. Late complications of ureteral stents. Eur Urol. 2000;38(1):41-44.
4. Sountoulides P, Pardalidis N, Sofikitis N. Endourologic management of malignant ureteral obstruction: indications, results, and quality-of-life issues. J Endourol. 2010;24(1):129-142.

5. Borofsky MS, Walter D, Shah O, et al. Surgical decompression is associated with decreased mortality in patients with sepsis and ureteral calculi. J Urol. 2013;189(3):946-951.

6. Izumi K, Mizokami A, Maeda Y, et al. Current outcome of patients with ureteral stents for the management of malignant ureteral obstruction. $J$ Urol. 2011;185(2):556-561.

7. Shaw GL, Choong SK, Fry C. Encrustation of biomaterials in the urinary tract. Urol Res. 2005;33(1):17-22.

8. Sancaktutar AA, Tepeler A, Soylemez H, et al. A solution for medical and legal problems arising from forgotten ureteral stents: initial results from a reminder short message service (SMS). Urol Res. 2012;40(3):253-238. 